\title{
OERlabs: Strategies for University-wide OER Advancement
}

\section{Sandra Hofhues, Bence Lukács}

Department of Education and Social Sciences, Faculty of Human Sciences, University of Cologne, Germany.

\begin{abstract}
As part of the project 'OERlabs - jointly training student(-teachers) for Open Educational Resources (OER) use' at the University of Cologne, Germany, various university stakeholders participated in an open developmental process through attending Multi-Stakeholder Dialogues (MSD). The goal was to sensitize and educate student teachers for Open Educational Resources. During a 6-month process the stakeholders collaboratively explored the challenges and developed solutions for initiating and advancing the use of OER during teacher training. This paper provides the solutions developed by the participants with the help of an impact-effort-matrix, which enabled the stakeholders to assess and evaluate all solutions accordingly. A key to this development was the participatory nature and open dialogue process among all relevant stakeholders, i.e. student teachers, administrators, lecturers and university leadership. A majority of the solutions can be described as low-effort but high-impact, therefore showing a promising outlook for further innovation and organizational development in regards to implementing new technologies.
\end{abstract}

Keywords: Organizational Development; Participatory Design; Open Educational Resources; Teaching Development; Open Education. 


\section{Open Educational Resources in Higher Education}

Ever since the Massachusetts Institute of Technology (MIT) decided to open up some of their courses and share their material publicly via the project 'Open Courseware' ("About OCW", n.d.) the trend for sharing educational content online started to grow. Along the same path the OECD and the UNESCO began to form an agenda and plan various directives to further open up education. Following these proclamations higher education institutions confirmed their motives in a survey for initiating and joining OER projects, namely being morally obliged to share educational resources, enabling all social groups to partake in education, being able to collaborate and cooperate with other institutions and move forward innovative thinking (see Goertz et al. 2007; Hylén, 2006).

In their 2007 world-wide market survey about OER at higher education institutions Goertz et al. discovered a heterogeneous field, wherein differences arose in terms of content, authoring, financing and target-audiences (2007, p. 14). Despite the continuous evolvement, and because of the heterogeneous range of OER initiatives, which were discovered, Goertz et al. concluded that two main factors have to be resolved: better extrapolation of content through transparency of platforms, and clear guidelines for OER (e.g. topics covered, repositories, target audience, authoring and financing) (2007, p. 17).

The work of the OERlabs project settled in between these goals and unfulfilled ideals to guide university stakeholders in jointly developing their university while continuing to work on advancing the 'greater good' of OER-use. As the following paper describes, organizational development is a complex undertaking and requires a specifically steered process (see Andrasch et al., 2018). The university stakeholders collaboratively worked and decided on solutions for OER advancement, which offer practical ideas that can be implemented without additional projects (i.e. funding), as well as potentially transferred to other higher education institutions.

\section{Innovation and Development in Higher Education}

In many cases, but especially when universities surpass a certain size (e.g. number of students and staff) it can be argued that the management of that type of institution increases exponentially. As Altvater (2007) argues, universities are very unique organizations that could indeed make use of external organizational consulting, but tend not to, because by its own admission a university contains enough experts and innovators in-house (cf. Mintzberg, 1983). But over the years external consulting has crept closer to working with universities through understanding its organizational 'peculiarities': Baecker (2007) describes the duality between organization and institution, wherein universities have an educational mandate, while also having to function effectively and efficiently on an organizational level. On the other hand, Cohen et al. (1972) used the term 'garbage can 
model' to describe higher education institutions, meaning that decisions are not made towards specific solutions, but are borne out of a congruence of: decision-making processes, the university stakeholders and their issues, i.e. random papers landing in the garbage can, but still piling up on one another. Lastly universities have been described as organizations that are comprised of 'loosely coupled systems', which in this case refers to the fact that decision-making processes tend to favor compromising solutions among the various institutions, people and their specific agenda, instead of specifically focused effort (Weick, 1976).

Through developing these concepts and methods, initiating change at universities has become its own specialty field, where not only change-management experts are consulted, but research projects are funded, which can deal with these experiences (Kühl, 2007). This is also where the current paper and the project OERlabs docks on. Innovating in the field of education encompasses various forms, and emerging technologies can be considered one of them. A question that has followed around educational institutions for many decades is how technical and social innovations can flourish and sustain. A leading model was developed by Rogers (2003) and is called 'diffusion of innovation'. Rogers (2002) describes diffusion as a social process, where communication takes place over time among the members of the relevant social system. The following part details how the developmental process in our project was encapsulated by the previously mentioned concepts, and followed Rogers' (2003) model.

\section{OERlabs: Multi-Stakeholder Dialogue process}

One of the key factors in innovating and developing new educational strategies is the participation of all relevant stakeholders. The project OERlabs therefore could draw from many important cohorts inside the university: students and student teachers, lecturers and seminar leaders, administrative staff, library personnel, as well as people form leadership positions. In order to be able to foster appropriate communication among all relevant stakeholders regularly scheduled events were organized, so called Multi-Stakeholder Dialogues (MSD) (Dodds \& Benson, 2013; Seufert, 2013). This process took place from the beginning of December until the end of April and consisted of three MSD events, while also providing stakeholders with the opportunity to communicate through various online modes during that same timeframe. This open developmental phase was meant to confront the stakeholders first with openness ideas and methods in general, while towards the final stages the scope narrowed (Andrasch et al., 2018). 


\section{Proposal of Solution - the outcomematrix}

The relevant stakeholders were asked to produce various challenges and appropriate solutions on how to advance the use of OER at the university. Throughout the process the challenges were formulated by the participants, based on their own experiences, as well as based on the discussions and tasks they encountered. The participants constantly shared their views, experiences and opinions during the work processes and also had to create the table and the matrix shown below in groups, and share their findings with the others.

Table 1. Solutions and Challenges developed by UoC stakeholders (translated from German and edited for clarity)

\begin{tabular}{|c|c|c|}
\hline Nr. & Proposed Solution & Challenge Encountered \\
\hline 1 & $\begin{array}{l}\text { A platform (i.e. the learning management } \\
\text { system ILIAS }{ }^{1} \text { ) for collecting material } \\
\text { from seminars }\end{array}$ & $\begin{array}{l}\text { Students would like to have access to } \\
\text { previously created seminar material }\end{array}$ \\
\hline 2 & $\begin{array}{l}\text { Have room for discussion in order to } \\
\text { enhance openness: teaching mistakes, } \\
\text { insecurities, failings }\end{array}$ & $\begin{array}{l}\text { Sharing is not common among teachers; } \\
\text { misunderstanding attitudes towards } \\
\text { mistakes, e.g. everything has to be perfect; } \\
\text { status of teachers not aligned with correct } \\
\text { perspective/role }\end{array}$ \\
\hline 3 & $\begin{array}{l}\text { Funding for learning and sharing, } \\
\text { similarly as for culture and economy (up } \\
\text { to this point only short-term solutions) }\end{array}$ & $\begin{array}{l}\text { Pay-structure for creating OER; } \\
\text { Otherwise time constraints for lecturers } \\
\text { and teachers }\end{array}$ \\
\hline 4 & $\begin{array}{l}\text { Kind of 'Social Media Training' for } \\
\text { teachers, i.e. get to know feedback } \\
\text { culture, engage in discussions, learn } \\
\text { formulation of criticism }\end{array}$ & $\begin{array}{l}\text { Teachers want to convince others to share } \\
\text { OER online, but there are reservations } \\
\text { about how their material will be received } \\
\text { by the community }\end{array}$ \\
\hline 5 & $\begin{array}{l}\text { Introduce minimal quality standards for } \\
\text { communities, which are provided } \\
\text { by/through the community }\end{array}$ & $\begin{array}{l}\text { Teachers are uncomfortable with others' } \\
\text { teaching material and wish for regulated } \\
\text { material instead; they instead choose not } \\
\text { to use OER }\end{array}$ \\
\hline 6 & $\begin{array}{l}\text { Using digital and analogue material for } \\
\text { PR-work (e.g. print-magazines, } \\
\text { homepage, social media channels); } \\
\text { finding examples of OER-use for }\end{array}$ & $\begin{array}{l}\text { Promotion of the university's OER- } \\
\text { activities; build and raise awareness for } \\
\text { OER at the university in order to motivate } \\
\text { students and teachers to create/use OER }\end{array}$ \\
\hline
\end{tabular}


university-context

Initiate a basic seminar where students learn about OER and how to use them

Only using correctly licensed material

OER platforms (e.g. provided by the university, government incl. visibility and support)

Platforms and/or sited with pictures and graphics

11 Offer trainings for teachers where the benefit of a sharing culture (i.e. online cooperation) is at the forefront Implementation of sharing and re-mix culture into the state bylaws for teacher education

Work together with information specialists (i.e. libraries); open-data technology; meta-data; central repository for OER; using existing publishing infrastructure

Teachers should not only create OER themselves, but encourage and teach their students to adapt the materials and integrate it into their personal learning environment; openness is also relevant for actual (learning and teaching) practice
Provide basic OER-information (principles, repositories etc.) through the homepage of the library Propose the use of OER in presentations
Student teachers should have more experiences with OER during their education (would lead to more awareness among teachers later on)

E.g. students want to share their re-mixed material; correct sourcing of the re-mixed material is necessary

Sharing my created material while reaching the biggest potential audience

Creating presentations for seminars, e.g. finding appropriate pictures (legality of use, sources, licensing issues)

Veteran teachers can have negative attitudes towards 'new' ideas and technology

Teachers have to be introduced to cooperation with the help of digital media

Creating OER-material and reaching audiences so it will be intensively used

OER do have benefits, but this potential is unused in terms of establishing OERpractices for the learners

\section{Raising awareness about OER among students and teachers}

Problems for documentation of conference at university institute, e.g. pictures/graphics have to be removed from presentations due to copyright issues 
17 Clear structure for re-mixing and re-using material, e.g. trainings and guidelines

18 Community building through platforms; train-the-trainer; hacky hour; selforganization and tagged material

\begin{abstract}
Netzwerk Medien ${ }^{2}$ has a broad consulting concept for OER-use; support would also entail OER-workshops
\end{abstract}

Technical platform, which enables comments, voting or peer-reviews; agreement about quality criteria and its assessment

$$
\begin{aligned}
& \text { Instead of providing schoolbooks with } \\
& \text { OER content, have the ability to create } \\
& \text { and use own material as OER (especially } \\
& \text { at the start of the project) }
\end{aligned}
$$

(Online) platform where people can find and share guidelines, correctly licensed, categorized and tagged material
Lecturers and teachers are unsure about copyright/legal situation of their material, i.e. they do not feel comfortable sharing

Service department support lecturers and teachers in their OER-use

Linking up interested parties (i.e. scaling OER-use)

Lecturers and teachers want a 'safe' legal environment in which they can create and use material

Ensuring the quality of the material

A funded project developed teaching material for higher education and wants to publish them via a repository (ideally Open Access), but copyright a major issue (e.g. schoolbook content), therefore material will not be published

Person XYZ would like to re-mix material, but is unable to find and categorize which material can be repurposed

An author created good material, but after using it once it is 'lost in the shuffle'

\section{Implications and Outlook}

After the conclusion of the developmental process, the university stakeholders provided a thorough and practical array of solutions. Having to think and organize their solutions based on the impact-effort-matrix the stakeholders were compelled to take on a more practical perspective as can be seen in Figure 1. In (theory and) practice universities can more easily decide which solutions are obtainable and can therefore more readily engage in

\footnotetext{
2 The Zentrum Netzwerk Medien is a competence center at the University of Cologne, which offers service and teaching support regarding media. Further information (in German): https://www.hf.uni-koeln.de/4000
} 
innovating and developing. This factor was key in the methodical decision of using the matrix. An immediate visual representation forced the stakeholders to take step back already during the creation process, and reflect on their past work, as well as their future engagement.

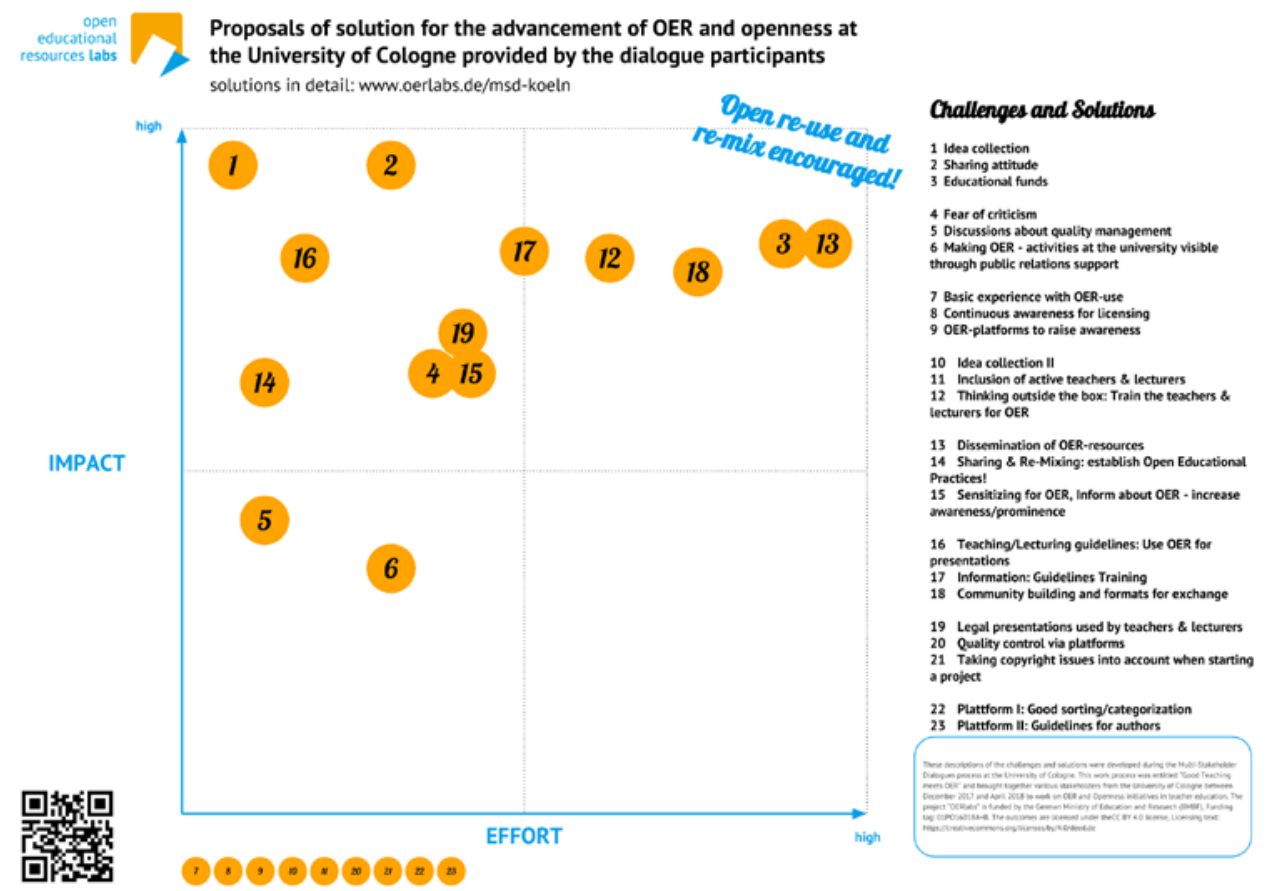

Figure 1. MSD4 Outcomematrix (translated form German, re-useable format via QR-code) (2018).

When discussing the proposed solutions in regards to furthering the use of OER, there seemed to be various clearly thought-out ideas provided: stakeholders see the need for sharing ideas, material and improving the cultural dialogue about sharing; there is a need for support/guidelines for students and teachers on how to find and use OER material; and lastly establishing a repository where material can be made available.

\section{References}

About OCW | MIT OpenCourseWare | Free Online Course Materials. (o. J.). Abgerufen 30. Januar 2019, von https://ocw.mit.edu/about/

Altvater, P. (2007). Organisationsberatung im Hochschulbereich-Einige Überlegungen zum Beratungsverständnis und zu Handlungsproblemen in Veränderungsprozessen. in Hochschulen, 11. 
Andrasch, M., Hofhues, S., \& Lukács, B. (2018). OERlabs: Empathy first, solution later? In 4th International Conference on Higher Education Advances (HEAD'18) (S. 12311238). Editorial Universitat Politècnica de València. https://doi.org/10.4995/HEAD18.2018.8182

Baecker, D. (2007). Das Personal der Universität. Diskussionspapier des Department for Communication \& Cultural Management, Zeppelin University, Friedrichshafen.

Cohen, M. D., March, J. G., \& Olsen, J. P. (1972). A garbage can model of organizational choice. Administrative science quarterly, 1-25.

Dodds, F., \& Benson, E. (2013). Multi-Stakeholder Dialogue. In Stakeholder Forum for a Sustainable Future. Johannesburg: Civicus.

Goertz, L., Johanning, A., \& Michel, L. P. (2007). Open Educational Resources an internationalen Hochschulen - eine Bestandsaufnahme. Essen: MMB Institut für Medien- und Kompetenzforschung.

Hylén, J. (2006). Open educational resources: Opportunities and challenges. Proceedings of Open Education, 4963.

Kühl, S. (2007). Von der Hochschulreform zum Veränderungsmanagement von Universitäten-Luhmann-Nacherzählung unter dem Gesichtspunkt der Reformierbarkeit von Universitäten. in Hochschulen, 1.

Mintzberg, H. (1983). Structures in fives. Designing effective organizations.

Rogers, E. M. (2002). Diffusion of preventive innovations. Addictive behaviors, 27(6), 989-993.

Rogers, E. M. (2003). Diffusion of innovations. New York: Free Press. Abgerufen von http://books.google.com/books?id=4wW5AAAAIAAJ

Seufert, S. (2013). Bildungsmanagement: Einführung für Studium und Praxis. Stuttgart: Schäffer-Poeschel.

Weick, K. E. (1976). Educational organizations as loosely coupled systems. Administrative science quarterly, 1-19. 